\title{
CRIATIVIDADE NA FORMAÇÃO DE PSICÓLOGOS: PERCEPÇÃO DE ALUNOS
}

\author{
Kelly Cristina de Lara Campos (Puc-Campinas/CNPq) ${ }^{1}$ \\ Walmor de Almeida Nogueira Largura (Puc-Campinas/CNPq) ${ }^{2}$
}

\begin{abstract}
Resumo
Este trabalho teve por objetivo avaliar a percepção dos alunos de $5^{\circ}$ ano de Psicologia sobre o conceito criatividade e sua importância na formação e no exercício profissional em Psicologia. Foram sujeitos 20 alunos de uma universidade privada, que responderam a um questionário contendo dados pessoais e quatro questões semi-abertas, versando sobre conceito de criatividade; percepção sobre sua própria criatividade; importância desta no trabalho do psicólogo; e o espaço propiciado no curso de Psicologia. Os resultados demonstraram que o conceito de criatividade para os sujeitos está ligado à busca de novas soluções, à inovação e a ser original, sendo que $85 \%$ dos sujeitos consideraram-se criativos. A cri atividade foi avaliada como importante para atuação do psicólogo (95\%), embora sua presença não seja sistemática na formação do psicólogo.
\end{abstract}

Palavras-chave: Criatividade; Formação em Psicologia; Atuação do psicólogo.

\section{Creativity in the Formation of Psychologists: Perception of Students}

\begin{abstract}
The aim of the study was to evaluate the student's perception about the concept of creativity and its importance in the formation and in the professional actuation of the psychologist of the students. They are students of the last year of undergraduate course of Psychology. The subjects were 20 students of a private university, that answered to a questionnaire concerning to personal data and four questions, about creativity concept; perception about its own creativity; importance of this in the psychologist' s work and the space propitiated to that issues in the course of Psychology. The results showed that the creativity concept for the subjects is tied up with the search of new solutions, the innovation and originality, and 85\% considered their own as creative persons. The creativity was evaluated as important for performance of the psychologist (95\%), although its presence in the psychologist' s formation is not systematic.
\end{abstract}

Key words: Creativity; Formation in Psychology; Professional Practice.

\section{INTRODUÇÃO}

A criatividade há muito tempo tem sido alvo de interesse de diversos autores em nível mundial. Esta temática vem sendo estudada e definida de diversas maneiras, o que sugere a existência de um fenômeno complexo e possuidor de múltiplas facetas. (Wechsler, 1998.)

Para uma melhor compreensão do que é criatividade, (Wechsler, 1998) analisa a evolução histórica deste conceito, que compreendeu inicialmente uma visão filosófica, em que criatividade

\footnotetext{
${ }^{1}$ Mestre em Psicologia Escolar pela PUC-Campinas

${ }^{2}$ Mestrando no curso de Psicologia Escolar da PUC-Campinas
} 
era considerada uma inspiração divina, na seqüência com a visão biológica e as contribuições de Darwin; tal conceito passou a ser visto como uma força criadora inerente à vida, e a hereditariedade era considerada seu principal componente.

Os enfoques psicológicos trouxeram contribuições para a melhor compreensão da criatividade, as teorias associacionistas e comportamentais por seus estudos sobre associações de idéias, a gestalt pela noção de pensamento produtivo, a psicanálise que acredita que criatividade era uma forma inconsciente de solução de conflitos, as teorias humanistas e seus conceitos de auto-realização etc. Todavia, nenhuma destas teorias por si só conseguiu abarcar toda amplitude do tema criatividade humana.

Os enfoques psicoeducacionais parecem ser aqueles que mais contribuíram para o amplo estudo do conceito de criatividade; vale lembrar nomes como Guilford (1967) e seu conceito de produção divergente; Torrance (1965) que, dentre diversos conceitos, trata também da combinação da produção convergente com a produção divergente, tendo desenvolvido diversos testes na área.

Além desses enfoques, o conceito de criatividade conta ainda com contribuições das teorias psico-fisiológicas que trazem a noção de domínio cerebral, as teorias sociológicas que destacam a questão dos efeitos do ambiente social no processo criativo, as proposições psicodélicas e a noção de expansão da consciência e há ainda apropriação instrumental na qual se destaca o conceito de analogias.

Como pode ser visto, as propostas que se interessaram por definir o conceito de cri atividade são as mais variadas possíveis, e todas buscam, de acordo com seu referencial, conhecer e esclarecer cada vez mais este conceito.

Wechsler (1998), ao tratar das concepções atuais, relata que os temas relacionados à criatividade vêm sendo agrupados em três grandes grupos, a saber: o processo criativo, a pessoa criativa e o produto criativo.

O processo criativo sofre influência de variáveis cognitivas, motivacionais, de personalidade etc. Quanto à pessoa criativa, sabe-se que todos têm esta capacidade, ainda que suas manifestações sejam diferentes; para a realização do potencial criativo é necessário contar com motivo, meios e oportunidades para isto. Por fim, o produto criativo (visível) deve conter novidade, relevância e elegância.

Pelo exposto, pode-se considerar que a criatividade é, sem dúvida, um dos muitos aspectos do comportamento e pensamento humano que merecem atenção constante da Psicologia; assim não é de estranhar que na literatura pertinente apareçam muitas definições, como as citadas a seguir.

Wechsler (1998, p. 40) baseando-se nas idéias de Torrance esclarece que a criatividade pode ser compreendida como um "processo de tornar-se sensível a falhas, deficiências na informação ou desarmonias; identificar as dificuldades ou os elementos faltantes; formular hipóteses a respeito das deficiências encontradas; testar e retestar essas hipóteses e, por último, comunicar os resultados encontrados".

Para Martinez (1995, p. 26) "a cri atividade é expressão da implicação da personalidade de uma esfera concreta de atividade, o produto da otimização de suas capacidades em relação com fortes tendências motivacionais, em que o sujeito da atividade está envolvido como um todo".

Já na visão de Guilford (1967), a criatividade é produto do chamado pensamento divergente, o qual é encarregado de procurar novas soluções e reconhecer problemas que outros passam por alto, sendo portanto uma atividade cognitiva que resulta em novas soluções para os problemas. 
Urquijo (1996) aponta que quase todos os autores que definem criatividade concordam quanto a um aspecto, que é o fato de este conceito estar ligado à possibilidade de gerar respostas originais.

Miel (1976), ao enfocar o conceito de criatividade no campo educacional, esclarece que a palavra criativo não é nova na área, e seu uso passou a ser mais freqüente no início da década de trinta. Desde então, diversos estudos sobre criatividade no âmbito escolar têm sido realizados. Para esta autora a criatividade é um meio de reação que está disponível para todos os seres humanos e permite enfrentar problemas, condições e oportunidades cada vez mais complexos. No contexto de ensino a criatividade pode trazer experiências emocionantes e satisfatórias tanto para o aluno quanto para o professor.

Acrescenta a mesma autora que "a criatividade é qualidade que todo ser humano pode demonstrar em sua maneira de viver. Todavia, os indivíduos diferem, tanto em resultado da sua natureza como da sua educação..." (p. 25), e complementa que é possível aumentar a criatividade na maioria dos indivíduos, colocando-se em prática o que se sabe e está presente na literatura sobre as condições que incentivam a criatividade. Desta forma podem ser oportunidades específicas para desenvolver a criatividade.

No campo escolar, o professor "tem abundante oportunidade de 'ser criativo' na maneira como lida com todas essas condições mutáveis. Se rejeita deliberadamente a alternativa de recair em uma reação habitual, sem pensamento, e toma conscientemente uma decisão baseada no exame dos fatores velhos e novos presentes numa situação, está-se empenhando em processo criativo" (Miel, 1976, p. 25).

O "produto" da criatividade do professor são as "oportunidades" que este cria, para que o indivíduo e os grupos experimentem e aprendam com todas as variáveis presentes na sala de aula, incluindo-se o tempo, espaço, as coisas, as próprias pessoas e o professor, que podem ser organizados e arranjados no intuito de levar o grupo à aprendizagem.

Bampi (1995) completa esta noção esclarecendo que "o professor criativo possui inspiração para desenvolver o conteúdo, procurando ligações com o cotidiano e a realidade dos alunos, dando sentido concreto ao conhecimento, possibilitando a descoberta e a organização de mais informações" (p. 11).

Silva (1994) afirma que não se deve tratar o pensamento criativo como um dom ou talento, e sim como algo que por meio das relações estabelecidas em sala de aula pode ser estimulado ou inibido.

Godoy (1996) amplia esta noção, esclarecendo que a inteligência também não é o fator-chave para que uma pessoa seja criativa, e sim que haja estímulos favoráveis em qualquer momento da vida, independendo ainda do extrato social ao qual o sujeito pertence.

Noller (1992, p. 189) afirma que "a função da escola é ensinar a pensar e isto só pode ser feito através do desenvolvimento da criatividade de cada aluno, fazendo alguma coisa acontecer dentro de cada aluno, ou seja, desenvolvendo a sua motivação interna" (p. 189).

Entretanto, estas noções não parecem fazer parte das práticas comuns entre os docentes; tanto as pesquisas de Torrance realizadas em 1965 quanto as de Wechsler e Richmond em 1984 constataram que a criatividade muitas vezes é punida em sala de aula, pois os professores preferem o aluno obediente e passivo, ao invés do aluno curioso e questionador; além disso, desde cedo os alunos são reforçados por seu "raciocínio lógico e convergente, em que todos os alunos devem 
sempre encontrar a melhor e única resposta para o problema em vez de possíveis soluções que responderiam à questão, ou seja, a utilização do pensamento divergente" (Torrance 1965, apud. Wechsler 1998, p. 42).

Alencar (1989) ressalta que países mais desenvolvidos utilizam-se de estratégias criativas para resolução de problemas; já o ensino brasileiro parece estar ainda voltado para o passado, adotando técnicas de memorização, de reprodução, e não preparando o aluno para os desafios futuros.

Wechsler (1996) relata ainda que a disciplina Criatividade nos Estados Unidos faz parte da maioria dos currículos de pós-graduação em Psicologia Educacional, enquanto que no Brasil ela ainda é pouco conhecida tanto em nível de graduação quanto de pós-graduação.

Nogueira (1992) demonstra esta realidade ao realizar um estudo sobre a criatividade no curso de Psicologia e conclui por um declínio da criatividade por parte destes estudantes do segundo ao quinto ano de suas formações universitárias, fato este bastante preocupante, uma vez que, como aponta Barbosa (1996), desenvolver a cri atividade durante a formação pode ser uma estratégia para gerar profissionais mais críticos e competentes.

Outra pesquisa realizada por Wechsler, Soligo, Crespo (1996) no curso de Psicologia buscou avaliar a opinião dos professores sobre a percepção da importância da disciplina criatividade na formação profissional; como resultados, encontraram definições de criatividade ligadas principalmente a aspectos como originalidade e inovação, seguidos por solução de problemas e mecanismo cognitivo.

Outra questão diz respeito à classificação da disciplina criatividade que para $50 \%$ dos sujeitos deveria ser eletiva e para $40 \%$ deveria ser obrigatória. A justificativa para que essa disciplina fosse eletiva levantou aspectos como "o psicólogo não necessita ser criativo", a "criatividade em excesso atrapalha" e "a grade curricular está lotada". A conclusão deste estudo aponta para um desconhecimento por parte dos professores quanto à importância da criatividade para o desempenho na área; deste modo, apesar das possíveis contribuições que poderiam ser alcançadas com a utilização da criatividade, isto quase nunca acontece, pois os professores desconhecem como aplicá-la.

Deste modo a criatividade, apesar de todo estudo científico já gerado sobre as suas inúmeras dimensões, parece ser ainda pouco compreendida, sendo percebida por muitos psicólogos e professores universitários como um fenômeno mágico, resultado da loucura, atividade artística ou passatempo etc. (Isaksen e Murdock, 1993 apud. Wechsler, 1996.)

Como resultado geral, percebe-se que muitas são as barreiras que influem na criatividade, pois o indivíduo que é diferente muitas vezes é excluído da sociedade, porque diverge das normas e rompe com os padrões preestabelecidos socialmente; estas são as chamadas barreiras culturais.

Por outro lado, existem também as barreiras perceptuais, que englobam a dificuldade do próprio indivíduo em perceber os problemas, a busca de soluções rápidas ou imediatas, o pensamento rígido, a inabilidade de ver os problemas por um novo enfoque e a dificuldade em suspender julgamentos e críticas; este tipo de barreira requer uma reestruturação cognitiva por parte do sujeito, a fim de tomar-se mais flexíve1. Além destas, existe ainda a barreira emocional, que se refere aos medos de fracasso, do desconhecido, do ridículo, a imaginação empobrecida, a evitação de frustrações etc. (Wechsler, 1998.)

De acordo com o exposto, mesmo diante das dificuldades encontradas, parecem ser muitas 
as vantagens proporcionadas pela criatividade no desenvolvimento humano, dentre as quais o surgimento de novas habilidades, talentos, inovações e a possibilidade de resolução de problemas; deste modo, torna-se relevante avaliar o espaço que a Psicologia tem proporcionado a esta temática, como forma de contribuição ao crescimento de seus futuros profissionais.

Assim sendo, os objetivos do presente trabalho foram: avaliar a percepção dos alunos de $5^{\circ}$ ano do curso de Psicologia em relação ao conceito de criatividade; conhecer o nível de informação que os alunos possuem sobre o conceito de criatividade; avaliar a percepção dos alunos em relação à sua própria cri atividade; verificar a importância atribuída à criatividade no trabalho do psicólogo e levantar qual é o espaço propiciado à expressão criativa no curso de psicologia.

\section{MÉTODO}

\section{Sujeitos}

Foram sujeitos desta pesquisa 20 alunos de $5^{\circ}$ ano do curso de Psicologia, sendo $80 \%$ do sexo feminino e $20 \%$ do sexo masculino. Quanto à faixa etária, $55 \%$ dos sujeitos estavam compreendidos entre a idade de 20 e 25 anos; 20\% apareceram entre 26 e 30 anos; e 15\% entre 31 e 35 anos; sujeitos com mais de 36 anos formaram 10\% da amostra.

Em relação à área de atuação escolhida pelos sujeitos, 85\% da amostra fazia estágio na área clínica, 10\% na área organizacional e 5\% estagia na área escolar.

\section{Instrumento}

Foi utilizado um questionário contendo dados pessoais e quatro questões semi-abertas, versando sobre: informação sobre criatividade; percepção dos alunos em relação à sua própria criatividade; importância atribuída à criatividade no trabalho do psicólogo; e espaço propiciado à expressão criativa no curso de psicologia.

\section{Procedimento}

Primeiramente obteve-se a autorização para a coleta de dados, junto à Coordenação da Universidade, esclarecendo-se os objetivos da pesquisa, garantindo sigilo das informações e se propondo a oferecer retorno das informações coletadas em caso de interesse.

Os instrumentos foram entregues aos alunos do $5^{\circ}$ ano do curso por um dos pesquisadores e deveriam ser preenchidos e devolvidos em um prazo de 48 horas. Inicialmente foram distribuídos 30 instrumentos, mas, deste montante, apenas 20 questionários foram respondidos.

\section{RESULTADOS}

Utilizou-se o teste do $c^{2}$ de homogeneidade a fim de verificar predomínios de categorias de respostas. Como base de cálculo, utilizaram-se as freqüências percentuais, adotando-se o nível de significância de 0,05\% (Witter, 1996).

Em relação à definição de criatividade dos sujeitos, 59,38\% dos sujeitos apontaram a categoria Encontrar novas soluções ou novas estratégias/Ser original como principal resposta, seguido da categoria Expressar-se livremente/desbloquear o pensamento (15,63\%) e Criatividade é 
transformar/melhorar o que já existe (12,50\%).

No que diz respeito à opinião dos alunos de psicologia sobre criatividade (Tabela 1), o quiquadrado observado foi de 120,18 $\left(\mathrm{c}^{2} \mathrm{c}^{=}=11,07\right.$; n.g.l. $=5$; n.sig. $\left.=0,05\right)$, apresentando maior concentração de resposta na categoria Encontrar novas soluções ou novas estratégias/ Ser original, o que levou a rejeição da hipótese nula.

Tabela 1 - Definição de criatividade.

\begin{tabular}{l|c|c}
\hline \multicolumn{1}{c|}{ Descritores } & F & F\% \\
\hline Encontrar novas soluções ou novas estratégias/Ser original & 19 & 59,38 \\
Expressar-se livremente/Desbloquear o pensamento & 5 & 15,63 \\
Criatividade é transformar/melhorar o que já existe & 4 & 12,50 \\
Desenvolver as habilidades cognitivas e pessoais & 3 & 9,38 \\
Descobrir caminhos diante da dificuldade/Ser flexível & 3 & 9,38 \\
Outros & 3 & 9,38 \\
\hline \multicolumn{1}{c|}{ Total } & $\mathbf{3 2}$ & $\mathbf{1 0 0 , 0 0}$ \\
\hline
\end{tabular}

Em relação ao ser ou não ser criativo, 85\% afirmaram que se consideravam pessoas criativas enquanto $15 \%$ da mostra responderam não serem pessoas criativas. Na justificativa quanto a ser criativo (Tabela 2), a categoria Gosto por inventar e inovar obteve cinco respostas (27,78\%), enquanto Atuar criativamente e transformar as coisas registrou quatro freqüências (22,22\%) e Ter idéias criativas obteve três respostas (16,67\%). As demais categorias tiveram duas respostas cada $(11,11 \%)$.

Na análise do desempenho nas categorias, o C20 resultou em 14,86, suficiente para mais uma vez rejeitar a hipótese nula $\left(\mathrm{c}^{2}{ }_{\mathrm{C}}=11,07\right.$; n.g.l. $=5$; n.sig. $\left.=0,05\right)$, provavelmente em razão de um maior desempenho nas categorias Gosto por inventar e inovar e Atuar criativamente e transformar as coisas.

As principais justificativas apontadas pelos sujeitos que se consideravam não criativos foram ter dificuldades de ousar, criar, ser metódica e não se preocupar em ser criativo.

Tabela 2 - Justificativa quanto a ser criativo.

\begin{tabular}{l|c|c}
\hline \multicolumn{1}{c|}{ Descritores } & F & F\% \\
\hline Gosto por inventar e inovar & 5 & 27,78 \\
Atuar criativamente e transformar as coisas & 4 & 22,22 \\
Ter idéias criativas & 3 & 16,67 \\
O trabalho, lazer ou estudo requer & 2 & 11,11 \\
O potencial criativo é inato & 2 & 11,11 \\
Outros & 2 & 11,11 \\
\hline \multicolumn{1}{c|}{ Total } & $\mathbf{1 8}$ & $\mathbf{1 0 0 , 0 0}$ \\
\hline
\end{tabular}

Para 95\% dos estudantes pesquisados, a criatividade é importante para o exercício da sua futura profissão e apenas $5 \%$ da amostra não consideraram a criatividade importante para a atuação profissional.

Nos motivos da importância atribuída à criatividade para psicólogo (Tabela 3), dez sujeitos indicaram a categoria Facilitar a atuação do psicólogo (41,67\%), seis sujeitos apontaram É 
importante para a solução de problemas (25\%), quatro apontaram É fundamental em todas as áreas de atuação humana (16,67\%) e três sujeitos referiram $\mathbf{O}$ psicólogo tem que ser inovador, dinâmico (12,50\%). Apenas um único sujeito indicou a categoria Outros (4,17\%).

Na comparação do desempenho dos grupos, o $\mathrm{c}^{2}{ }_{\mathrm{o}}$ foi calculado em 40,63 , levando mais uma vez à rejeição da hipótese nula $\left(c^{2}{ }_{c}=9,49 ;\right.$ n.g.l. $=4$; n.sig. $\left.=0,05\right)$ em razão do maior desempenho na categoria É importante para atuação do psicólogo.

Tabela 3 - Motivo da importância atribuída à criatividade para psicólogo.

\begin{tabular}{l|c|c}
\hline \multicolumn{1}{c|}{ Descritores } & F & F\% \\
\hline Facilitar a atuação do psicólogo & 10 & 41,67 \\
É importante para a solução de problemas & 6 & 25,00 \\
É fundamental em todas as áreas de atuação humana & 4 & 16,67 \\
O psicólogo tem que ser inovador, dinâmico & 3 & 12,50 \\
Outros & 1 & 4,17 \\
\hline \multicolumn{1}{c|}{ Total } & $\mathbf{2 4}$ & $\mathbf{1 0 0 , 0 0}$ \\
\hline
\end{tabular}

Na avaliação que os sujeitos formularam do espaço para a expressão da criatividade propiciado pelo curso de psicologia (Tabela 4), 12 sujeitos indicaram que este espaço ocorre Às vezes (60\%), seguido de Raramente e Freqüentemente com três respostas cada (15\%). As categorias mais polarizadas, Sempre e Nunca, obtiveram uma única resposta cada (5\%).

A análise através do $c^{2}{ }_{c}$ apontou para o valor de 105,00, determinando mais uma vez a rejeição da Ho $\left(c^{2}{ }_{C}=9,49\right.$; n.g.l. = 4; n.sig. $\left.=0,05\right)$ em razão do maior desempenho na categoria Às vezes.

Tabela 4 - Você acredita que o curso de Psicologia propicia espaço para a expressão da criatividade.

\begin{tabular}{lc|c|c}
\hline & Descritores & $\mathbf{F}$ & $\mathbf{F \%}$ \\
\hline Nunca & & 1 & 5,00 \\
Raramente & 3 & 15,00 \\
Às vezes & 12 & 60,00 \\
Freqüentemente & 3 & 15,00 \\
Sempre & 1 & 5,00 \\
\hline \multicolumn{2}{c}{ Total } & $\mathbf{2 0}$ & $\mathbf{1 0 0 , 0 0}$ \\
\hline
\end{tabular}

Em relação às justificativas apresentadas para a avaliação do espaço propiciado na formação do psicólogo para a expressão da criatividade (Tabela 5), os sujeitos que indicaram as freqüências nunca ou raramente apontaram que o Curso não estimula o pensamento e Informações prontas em duas oportunidades cada (40\%) e Falta de iniciativa uma única vez (20\%). Os sujeitos acabam por apontar principalmente para falhas curriculares ou didático-pedagógicas do curso para justificar sua resposta, embora um sujeito considere o aspecto individual.

Os sujeitos que responderam na alternativa às vezes referiram em $12,50 \%$ das respostas Modelo Pronto, sendo que os itens Falhas curriculares, Estratégia didático-pedagógica e Depende da matéria/professor apareceram com três respostas cada (18,75\%). A categoria Falta de estímulo e oportunidade ocorreu cinco vezes $(31,25 \%)$, sendo a mais referenciada. 
Já as alternativas freqüentemente e sempre receberam quatro respostas na categoria Psicologia favorece criatividade (80\%) e uma única resposta em Depende do aluno (20\%). Este ponto toma-se interessante, pois os alunos acreditam que a Psicologia é um campo que dá margem para a utilização dos aspectos criativos por seu amplo conteúdo e necessidade de novas soluções.

Tabela 5 - Justificativa da avaliação do espaço propiciado na formação do psicólogo para a expressão da criatividade.

\begin{tabular}{c|c|c|c}
\hline Descritores & Categoria & $\mathbf{F}$ & $\mathbf{F \%}$ \\
\hline Nunca/ Raramente & Curso não estimula o pensamento & 2 & 40,00 \\
& Informações prontas & 2 & 40,00 \\
& Falta de iniciativa & 1 & 20,00 \\
\cline { 2 - 4 } & Total & $\mathbf{5}$ & $\mathbf{1 0 0 , 0 0}$ \\
\hline \multirow{5}{*}{ Às vezes } & Modelo Pronto & 2 & 12,50 \\
& Falhas curriculares & 3 & 18,75 \\
& Estratégia didático-pedagógica & 3 & 18,75 \\
& Falta de estímulo e oportunidade & 5 & 31,25 \\
& Depende da matéria/professor & 3 & 18,75 \\
\cline { 2 - 4 } & Total & $\mathbf{1 6}$ & $\mathbf{1 0 0 , 0 0}$ \\
\cline { 2 - 4 } Freqüentemente/Sempre & Psicologia favorece criatividade & 4 & 80,00 \\
& Depende do aluno & 1 & 20,00 \\
\cline { 2 - 4 } & Total & $\mathbf{5}$ & $\mathbf{1 0 0 , 0 0}$ \\
\cline { 2 - 4 } & &
\end{tabular}

\section{DISCUSSÃO E CONSIDERAÇÕES FINAIS}

Cabe inicialmente um alerta decorrente das limitações da amostra e do instrumento utilizado requerendo cuidado na generalização dos dados e a realização de réplica da pesquisa.

O conceito de criatividade para a maior parte dos alunos de Psicologia pesquisados parece estar ligado à busca de novas soluções, à inovação, ao encontro de diferentes estratégias que visem solucionar problemas e também a um outro aspecto que é o de ser original, fazer coisas novas. Dados semelhantes foram encontrados na pesquisa realizada por Wechsler, Soligo e Crespo (1996), com professores de Psicologia, que citaram aspectos como originalidade, inovação e solução de problemas. Deste modo, observou-se semelhança entre a opinião de alunos e professores de Psicologia quanto ao conceito de criatividade.

Embora as definições de criatividade possam incluir outros aspectos relacionados ao tema, pode-se também observar uma convergência entre os dados obtidos nesta pesquisa e o encontrado na literatura, especialmente a visão de Guilford (1967), que esclarece que através do pensamento divergente as pessoas podem chegar a encontrar novas soluções para os problemas. Outro fato acordado na literatura (Urquijo, 1996) é que quase todas as definições de criatividade trazem a noção de que esta propicia o surgimento de respostas originais, fato este apontado pelos sujeitos desta pesquisa.

Em relação à percepção dos alunos sobre serem ou não criativos, 85\% dos sujeitos 
consideram-se criativos, e as justificativas apresentadas para tal avaliação se distribuíram em diversas categorias, tendo prevalecido o fato de gostar de inventar e inovar, bem como atuar criativamente e transformar as coisas, fatores estes que parecem estar mais relacionados a uma motivação interna. As justificativas dos sujeitos, portanto, refletiram também as definições de criatividade por eles forneci das, demonstrando consistência interna nos seus conceitos pessoais, indo mais uma vez de encontro aos postulados de Guilford (1967). Entretanto, seria necessário analisar a criatividade usando um instrumento específico para comparar com o auto-ajustamento feito pelos alunos para verificar se realmente desenvolve seu potencial criativo.

Já aqueles que disseram não serem criativos justificam-se principalmente por ter dificuldade de ousar, criar e por ser metódico, aspectos que parecem estar ligados às barreiras perceptuais descritas por Wechsler (1998).

Para 95\% dos sujeitos a criatividade é importante para a profissão de psicólogo, e os principais motivos apontados para tal relevância dizem respeito à criatividade enquanto facilitadora da atuação do Psicólogo nas diferentes áreas, seja na clínica, escola, empresa ou outros, onde o psicólogo pode trabalhar. Além deste ponto, surge novamente a questão da possibilidade de solução de problemas que a criatividade pode proporcionar. Estes dados sugerem que os alunos possuem conhecimento das possíveis contribuições fornecidas pela criatividade ao futuro profissional; este ponto vai ao encontro da literatura, ao se observar, por exemplo, que autores como Barbosa (1996) quando afirma que desenvolver a criatividade durante a formação pode ser uma estratégia para gerar profissionais críticos e competentes.

Vale ressaltar a consideração positiva feita pelos alunos de psicologia em relação à criatividade e sua grande contribuição para a melhor atuação profissional; este ponto deveria ser melhor considerado quando do planejamento do currículo do curso de Psicologia, que como apontam Alencar (1989) e Wechsler (1996) vêm recebendo pouca importância no Brasil, sendo criatividade um conceito pouco conhecido e desenvolvido tanto na graduação como na pósgraduação. Talvez por isto, a grande maioria dos sujeitos tenha indicado que o espaço para a expressão da criatividade na formação em Psicologia não é sistemático, posto que depende muito mais de uma estratégia didático-pedagógica do que um objetivo principal desta formação. Ao que parece, na formação do Psicólogo se desconhece o proposto por Miel (1976) sobre a importância da criatividade no campo educacional.

Os sujeitos que não reconhecem a criatividade no curso de psicologia alocam suas respostas em elementos exclusivos do curso, enquanto os que percebem uma ocorrência não sistemática corroboram a posição explicitada na literatura sobre as barreiras e dificuldades enfrentadas pelas pessoas na expressão de sua criatividade no dia-a-dia (Wechsler, 1998). Por fim, os que percebem este espaço de modo constante indicam que a Psicologia é um campo que dá margem para a utilização dos aspectos criativos por seu amplo conteúdo e necessidade de novas soluções, independente de aspectos didático-pedagógicos.

Assim, neste estudo foi possível verificar que os alunos possuem conceito de criatividade semelhante ao proposto por Guilford (Urquijo, 1996), se considerando criativos em sua maioria.

De modo geral, os sujeitos atribuem alta importância à criatividade no trabalho do psicólogo, embora indiquem que o espaço para seu desenvolvimento e expressão não seja sistemático.

Seria interessante se os estudos futuros nesta área controlassem duas variáveis importantes. A primeira diz respeito ao modelo teórico adotado que pode facilitar ou dificultar a expressão da 
criatividade. A segunda é relativa à área de atuação escolhida como principal pelo graduando, o que pode estar influenciando nessa questão.

Os dados obtidos, as bases apresentadas na introdução e na discussão dos resultados sugerem a necessidade de se cuidar curricularmente da criatividade no currículo da Psicologia como disciplina ou tópico específico em várias disciplinas, bem como tema que requer dos professores cuidado especial para que o futuro psicólogo seja criativo na sua atuação dentro dos parâmetros do científico e eticamente estabelecido.

\section{REFERÊNCIAS}

Alencar, E. S. (1989) A Repressão ao Potencial Criador. Psicologia: Ciência e Profissão. 9: 11-13.

Bampi, M. L. F. (1995) Efeito de um Programa para Desenvolvimento da Criatividade na Escrita. Dissertação de mestrado em Psicologia Escolar, Puccamp: Campinas.

Barbosa, A. J. G. (1996) Avaliação da Criatividade em Graduandos de Psicologia frente aos problemas escolares. Resumos do III Congresso Nacional de Psicologia Escolar, Rio de Janeiro.

Godoy, M. F. G. (1996) Criatividade e Integração Vital com Idosos. Dissertação de Mestrado em Psicologia Escolar, Puccamp: Campinas.

Guilford, J. P. (1967) The nature of human intelligence. Nova York: MacGraw Hill.

Martinez, A. M. (1995) Criatividade, personalidade e educação. Campinas: Papirus.

Martinez, A. M. (1995) Criatividade, personalidade e Educação. Campinas: Papirus.

Miel, A. (coord.) (1976) Criatividade no Ensino. São Paulo: Ibrasa.

Nogueira, A. E. B. (1992) Criatividade e Percepção do Futuro profissional em Estudantes de Psicologia. Dissertação de Mestrado, Puccamp: Campinas.

Noller, R. (1992) The importance of developing creativity in the schools. Anais do I Congresso Nacional de Psicologia Escolar. Valinhos: Átomo.

Siegel, S. (1975) Estatística Não Paramétrica para Ciências dos Comportamentos. São Paulo: McGraw-Hill.

Siíva, C. J. (1994) Cri atividade: Bem-me-quer, Malme-Quer. Em Alencar, E. M. L. \& Virgolim, A. M. R. (orgs.) - Criatividade: Expressão e desenvolvimento. Petrópolis: Vozes.

Torrance, E. P. (1965) Rewarding creative behavior. New Jersey: Prentice Hall.

Urquijo, S. (1996) Criatividade: Relações entre as concepções Fatorialistas e Piagetiana. Dissertação de mestrado em Educação. Universidade Estadual de Campinas: Campinas.

Wechsler, S. M. (1996) Criatividade e Psicologia Escolar: Implicações da Pesquisa para prática. Em Novaes, M. H. \& Brito, M. R. F. Psicologia na Educação: Articulação entre Pesquisa, Formação e Prática Pedagógica. Coletâneas da Anpepp, V. 1, n. 5,53-60.

Wechsler, S. M.; Soligo, A. F.; Crespo, M. L. F. (1996) A importância da Disciplina Criatividade no Currículo de Psicologia: Opinião de Professores Universitários. Resumos do III Congresso Nacional de Psicologia Escolar, Rio de Janeiro.

Wechsler, S.M. (1998) Criatividade Descobrindo e Encorajando. 2a. tiragem: Editora Psy.

Witter, G. P. (1996) Pesquisa científica e nível de significância, Estudos de Psicologia. 13 (1):55-63.

Recebido em 20/1 0/00

Revisado em 27/12/00

Aprovado em 20/04/01

Endereço para correspondência:

Rua Joaquim de Azevedo Queiróz, 44 Jardim das Paineiras - Campinas/São Paulo CEP: 13.093-433

E-mail: wlargura@zaz.com.b 